\title{
Knowledge of Preconception Healthcare and Associated Factors: A Study among Mothers in Jinka Town, Southern Region, Ethiopia
}

\author{
Kassahun Fikadu Tesema ${ }^{D},{ }^{1}$ Tamirat Cheneka, ${ }^{1}$ Alemayehu Alemu, ${ }^{1}$ Mekonen Feyissa, ${ }^{1}$ \\ Birhanu Birkaye, ${ }^{1}$ Hafiza Mohammed, ${ }^{1}$ Eleni Kidu, ${ }^{1}$ Getahun Wegaso, ${ }^{1}$ \\ and Biresaw Wasihun ${ }^{2}$ \\ ${ }^{1}$ Department of Midwifery, College of Medicine and Health Sciences, Arbaminch University, Arba Minch, Ethiopia \\ ${ }^{2}$ Maternal and Reproductive Health at Arba Minch University, Midwifery Department, Arba Minch, Ethiopia \\ Correspondence should be addressed to Kassahun Fikadu Tesema; kasfika@gmail.com
}

Received 19 August 2020; Revised 5 February 2021; Accepted 10 February 2021; Published 28 February 2021

Academic Editor: Antonio M. Rabasco

Copyright (C) 2021 Kassahun Fikadu Tesema et al. This is an open access article distributed under the Creative Commons Attribution License, which permits unrestricted use, distribution, and reproduction in any medium, provided the original work is properly cited.

\begin{abstract}
Background. Preconception healthcare is promising to improve the reproductive health status of women and couples if they receive care three months to two years before conception. In the current context of Ethiopia, however, preconception healthcare is overlooked in the continuum of care. Therefore, this study aimed to assess the knowledge of preconception healthcare and associated factors: a study among mothers in Jinka town, southern region, Ethiopia. Methods. A community-based cross-sectional study was employed among 522 randomly selected women of childbearing age who are living in Jinka town from March to April 2018. The study considers all the kebeles in the town. Study subjects were determined using proportionate-to-population size allocation. Then, a systematic random sampling technique was applied. Data were collected using a semistructured and pretested questionnaire. Descriptive summary data and binary logistic regression analysis were carried out to identify factors with the $95 \%$ confidence level and a $p$ value of less than 0.05 . Results. A total of 513 study subjects participated in this study. The overall preconception healthcare knowledge score of women in Jinka town was 51.1\%. In the multivariable analysis, housewives $(\mathrm{AOR}=2.93 ; 95 \% \mathrm{CI}: 1.38-6.19)$, an education level of at least college $(\mathrm{AOR}=3.79 ; 95 \%$ CI: $1.75-8.23)$, no history of neonatal death $(\mathrm{AOR}=4.13 ; 95 \% \mathrm{CI}=1.39-12.25)$, and the use of family planning methods $(\mathrm{AOR}=2.38$; 95\% CI: 1.49-3.79) increased the probability of preconception healthcare knowledge compared to the counterparts. Conclusion. In this study, women's knowledge of preconception healthcare was found borderline. The identified factors were housewife, education level of at least college, no history of neonatal death, and using family planning methods. Therefore, emphasizing these factors for the enhancement of women's knowledge of preconception healthcare is a necessary step.
\end{abstract}

\section{Introduction}

Preconception care aims to enhance health before conception by facilitating risk screening, health promotion, and effective interventions as a part of routine healthcare [1]. Besides, it has a high impact if all reproductive age couples become involved, whether or not they are contemplating pregnancy [2]. Most girls become pregnant before they know that they are pregnant [3]. In most low-income settings, however, maternal healthcare does not start until pregnancy is well established, not until quite half of the pregnancy has passed [4]. Others enter into the pregnant state without having optimal health status while practising risky health behaviours; all imply that there is a gap in the continuum of care given to childbearing women $[1,5]$.

There is growing evidence that shows the implementation of preconception care initiatives in low- and middleincome countries (LMIC) [5-8]. Due to the implementation of preconception healthcare initiatives, women and her fetus have a healthy gestation and beyond. Nevertheless, additional evidence is required to see the effectiveness of interventions where the worth of primary service integration is promoted. It is also an economical and socially acceptable way of providing primary preventive look after for all couples of childbearing age who are getting to have a healthy pregnancy outcome [1]. 
Receiving inadequate or no preconception care increases the magnitude of unplanned pregnancies, during which rates of maternal and infant death rate are linked to a scarcity of access to preconception care [7,9]. Research has speculated that about $35 \%$ of pregnancies with untreated gonococcal infections ended in low birth weight infants or premature deliveries, and up to $10 \%$ of this leads to perinatal death [5]. In this regard, the danger of lower birth weight and preterm delivery often increases in subsequent pregnancies $[10,11]$.

Moreover, women who are not planning a pregnancy, quitting cigarettes smoking, and have a habit of substance use before conception have an increased risk of adverse maternal and child health outcomes [7, 12, 13]. Poor maternal outcomes such as chronic hypertension, preeclampsia, and placental abruption [14, 15] possess an increased risk of adverse birth outcomes [16]. Women's awareness of preconception healthcare, which emphasizes on the preexisting condition of women [17], can reduce the danger of adverse pregnancy outcomes at large $[18,19]$.

For example, with the implementation of a comparatively simple intervention such as folic acid supplementation, immunization, and lifestyle modifications before pregnancy can reduce adverse pregnancy outcomes [20-22]. During this, cessation of tobacco exposure or elimination of cigarette smoking alone can reduce the typical of $6.5 \%$ and $23.5 \%$ of preterm delivery and sudden infant death rate, respectively [5].

Studies in low-income countries including Africa revealed low preconception healthcare knowledge that targeted the reproductive age group women. As an example, a study conducted in Malaysia reported that almost $52 \%$ of girls who had visited maternity clinics had satisfactory knowledge of preconception healthcare [23]. Another study in Egypt speculated that about 39\% of girls attending antenatal care knew the role of folic acid supplementation within the prevention of fetal malformations [24]. Research findings in Nigeria and Sudan also showed that women's knowledge of seeking preconception health interventions was reported very low $[25,26]$. Research findings in Ethiopia indicated that mothers who had good knowledge regarding preconception healthcare are low. For instance, a community-based study in Wolayita [27] and Gojjam [28], Ethiopia, showed that $53 \%$ and almost $28 \%$ of mothers knew preconception healthcare, respectively. Even though it is essential, preconception health is yet not integrated into the present healthcare system in Ethiopia [29, 30]. Hence, preconception healthcare may be a missed opportunity that the maternal healthcare system of Ethiopia should account for [13]. During a remote health setting where the notice of preconception health is low, the promotion of preconception health is, therefore, necessary either to spice up the continuum of care and reduce adverse pregnancy outcomes. Besides, evidence of women's knowledge of preconception health and associated factors in the study area are scarce. This study aimed to assess knowledge of preconception healthcare and associated factors: a study among mothers in Jinka town, southern region, Ethiopia.

\section{Methods and Materials}

2.1. Study Setting, Design, and Period. Jinka is an administrative town located $560 \mathrm{~km}$ far away from Hawassa and $750 \mathrm{~km}$ from Addis Ababa, at latitude and longitude of $5^{\circ} 47^{\prime} \mathrm{N} 36^{\circ} 34^{\prime} \mathrm{E} / 5.783^{\circ} \mathrm{N} 36.567^{\circ} \mathrm{E}$. The town is an administrative town of South Omo Zone within the Southern Nations, Nationalities and Peoples' Region. Within the year 2018, the entire population estimated was 30493, including 15217 (49.9\%) males and 15276 (50.1\%) females. Of the entire females, $7103(23.3 \%)$ were in their reproductive age group [31]. Jinka town has one general hospital, two health centres, and 6 health posts. Community-based cross-sectional study was conducted among a randomly selected 522 women from March to April 2018 in Jinka town administration.

2.2. Population. All of the mothers within the reproductive age group who live in Jinka town were the target group. Women of the reproductive age group who live in the selected kebeles of Jinka during the study period were the study population. Women of the reproductive age group who live in Jinka town for 6 months were included. During this study, women with hearing problems and important illness were not eligible.

2.3. Sample Size Determination and Sampling. The sample size was determined using a single population proportion formula $\left(n=Z^{2} p(\mathrm{p}-1) / d^{2}\right)$ considering the following assumptions: $27.5 \%$ of the proportion of women's knowledge of the previous study in Northern Ethiopia [28], a confidence interval (CI) of $95 \%$, a marginal error $(d=4 \%)$, and $10 \%$ nonresponse rate. Based on this, the final estimated sample size was 527. A simple random sampling technique was applied to select households from six kebeles of Jinka town. The household number was determined using an updated list of the kebeles administrative office. Then, a computergenerated simple random sampling technique was employed. The number of households eligible to be interviewed was estimated using proportional to size allocation. Using proportional to size allocation, the probability of women being selected is proportional to the size of the overall women of the reproductive age group in the selected kebele, giving the kebeles with larger proportion had a greater probability of selection while the smaller one had lower probability. A lottery method was applied when more than one candidate was found per household. Revisiting 
helps to reduce the number of nonresponses when the interviewee is not present during the data collection day.

\section{Operational Definition}

3.1. Knowledge. Women's knowledge of preconception healthcare was measured using thirteen items of preconception healthcare questions.

3.1.1. Good Knowledge. The knowledge index was built from answers to 20 questions on how diabetes mellitus should be treated and controlled before conception [2], epilepsy should be treated before conception [3], uncontrolled obesity affects fetal health [4], screening for STI and HIV/AIDS improves fetal life [5], heart disease should be treated before conception [6], stress before conception affects fetal life [7], screening for a genetic problem before conception lowers adverse pregnancy outcome [8], cigarette smoking should be avoided before conception [9], alcohol consumption before conception results in poor pregnancy outcome [10], exposure to environmental hazards before conception leads to adverse perianal outcome [11], habit of illegal drug intake before conception affects fetal wellbeing [12], routine female genital mutilation complicates childbirth [13], maintaining prepregnancy weight prevents adverse pregnancy outcome [14], avoiding cigarette smoking before conception can be a must [15], avoid alcohol consumption before conception is mandatory [16], tetanus vaccination prevents neonatal infection [17], having regular medical check-up helps to realize health pregnancy outcome [18], getting folic acid and vitamin supplements before conception lowers probability of fetal malformation [19], creating a healthy environment before conception benefits pregnancy [20], and planning pregnancy helps to realize healthy pregnancy outcome. Where a participant answered "yes" or "no" to all or any questions. Based on the answers to those questions, the index knowledge was categorized as having good knowledge (score 10-20).

3.1.2. Poor Knowledge. The knowledge index was built from answers to the 20 questions, and based on the answer of those questions, the knowledge index was categorized as having poor knowledge (score less than 10). A pretested, interviewer-administered, structured data collection instrument was developed adopting from literature based on the study objectives $[26,28,32,33]$. The questionnaire was divided into data that were collected divided into sociodemographic characteristics, birth outcome events, chronic illness profiles, general awareness of preconception healthcare, and knowledge of preconception healthcare.

The reliability coefficient was computed using SPSS version 26 window-compatible software. The overall across-item reliability coefficient of the instrument was 0.849 . On the contrary, content validity was assessed by three independent maternal and child health experts at Arba Minch University, and therefore, the average content validity index score of $86 \%$ was noted. Each question had one correct response where those that score above the mean of knowledge measuring questions are labelled as women having good knowledge.
3.2. Data Collection and Management. Primarily, the questionnaire was prepared in English and translated into the Amharic version using language experts. Face-to-face interview was conducted using the Amharic version. For data analysis, the Amharic version was reverted to the English version to keep the data consistent and clear. Data collection was conducted using five diploma midwives. The involved data collectors and supervisors were fluent in speaking the local language and had similar communitybased experiences. Two BSc midwives who had previous experience were hired for supervision. Completeness and consistency of the questionnaires were checked before, during, and after the data collection period. The principal investigator and the supervisors checked the data for missing values and completeness; corrective measures were taken accordingly. Data collectors and supervisors were trained for 2 days on the questionnaire, data collection procedure, confidentiality, and consent.

3.3. Data Analysis and Interpretation. Data were checked manually for consistency and completeness at the site of data collection. Then, the cleaned data were entered into EPI info version 7.2 and exported to a Statistical Package for Social Science (SPSS) version 26 windows compatible software for analysis. Descriptive summary statistics, such as percentage and frequency, were computed and presented in tables and graphs. To identify associated factors with women's knowledge of preconception healthcare, bivariate logistic regression was performed for each independent variable and dependent variable. Independent variables with a $p$ value of less than 0.2 in the bivariate analysis were included in the multivariable analysis. A $p$ value of $<0.05$ or $95 \%$ confidence interval excluding 1 in the multivariable analysis was considered statistically significant.

\section{Results}

4.1. Sociodemographic Characteristics. From a total of 522 study subjects, 513 participated in this study, which gives a response rate of $98.7 \%$ (Figure 1).

The median age of the respondents was 24 years. Three hundred and thirty-seven (65.7\%) of the study participants were married. The majority, 257 (50.1\%) of study subjects were Orthodox Tewahido religion followers, while the rest 188 (36.6\%) and $62(12.1 \%)$ were protestant and Muslim religion followers, respectively. Nearly sixty percent of the study subjects had Mali ethnic background followed by about $28 \%$ of Amhara ethic dwellers. In this study, the percentage of women who have no formal education was $13.3 \%$. The majority of the 208 (40.5\%) of them were housewives. Study participants had a proximate record in terms of educational status; 157 (30.6\%) of them had achieved primary education level while secondary education level was followed by 155 (30.2\%). The majority, 377 (73.5\%) of study subjects have used their mobile phones to access health related information, while the rest 241 (46.9\%) and 97 (18.9\%) were using radio and television. In this study, nearly $8 \%$ had no regular access to any of the abovementioned means of communication (Table 1). 


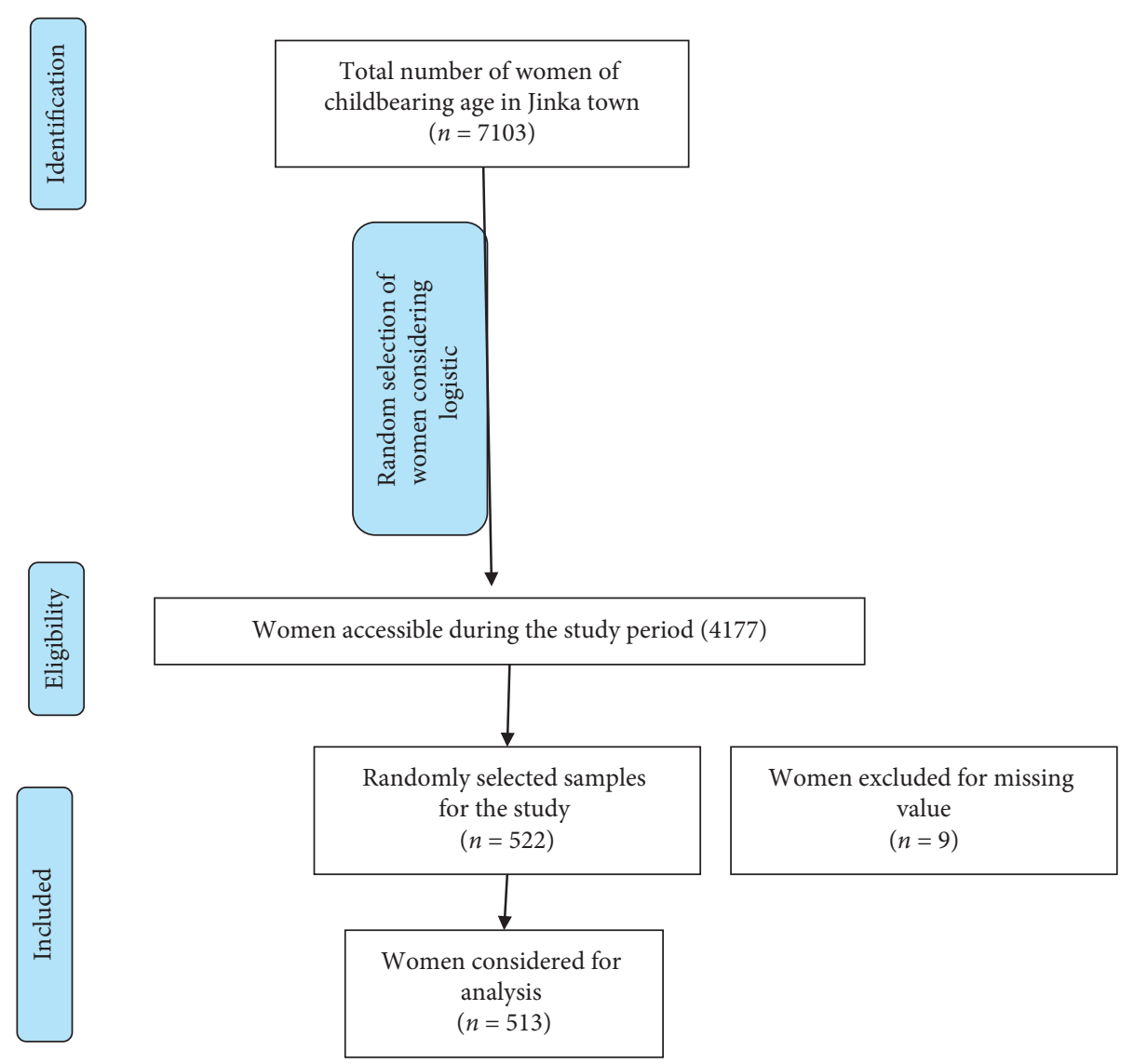

Figure 1: Flow chart for included and excluded study participants in a preconception knowledge assessment study conducted among women of reproductive age living in Jinka town, Southern Ethiopia.

4.2. Adverse Birth Outcome Events of Reproductive Age Women. Among the 513 respondents, 333 (64.9\%) had reported that they were pregnant before. Of the total participants, $34(10.2 \%)$ had an unintended pregnancy history. Of the $71(21.3 \%)$ study participants who had an episode of abortion, 53 (10.3\%) of them had completed spontaneously. Regarding the history of poor obstetric events, women who had a stillbirth, neonatal death, preterm birth, and congenital anomaly were $5.4 \%, 7.5 \%$, and both preterm birth and congenital anomaly had shared $2.10 \%$, respectively.

\subsection{Chronic Health Illness Profile and Social Behaviour.} Of the 513 women, 484 (94.3\%) of them drank no alcohol, while $496(96.7 \%)$ of them responded that they were not smoking. Of the total participants, $304(59.3 \%)$ had used at least one family planning method. Regarding the history of existing health conditions, sixty-five (12.7\%) women had at least one confirmed chronic illness. In this study, women with diabetics mellitus were 22 (33.8\%) (Figure 2).

4.4. Women's Awareness of the General Concept of Preconception Care. The overall preconception healthcare knowledge score of women in Jinka town was 51.1\%. Among the 513 participants, $312(60.8 \%)$ of them have heard about preconception care before. The most frequently mentioned source of information about preconception healthcare was health institutions, where it accounted for 247 (48.1\%). The remaining included mass media (19.55\%), family/relatives (15.1\%), school, and friends (10.89\%) (Table 2).

4.5. Women's Knowledge of Preconception Health and Behavioural Risk Factors on the Fetus. Results of women's knowledge of risk factors towards pregnancy outcome: STIs including HIV/AIDS (80.3\%), untreated obesity (49.7\%), cigarette smoking (86.7\%), alcohol consumption (83.0\%), female genital mutilation (74.5\%), and genetic problems (47.4\%) were sexual and behavioural conditions of preconception healthcare (Table 3).

4.6. Women's Knowledge of Changes Should Be Made before Pregnancy. Creating a healthy living environment (83\%), having a planned pregnancy $(82.7 \%)$ and medical screening (51.5\%), avoiding cigarette smoking (79.3\%), and getting a vaccination (66.6\%) and folic acid supplementation (30.6\%) were conditions where women should be aware before conception (Figure 3).

4.7. Factors of Knowledge of Preconception Care. Results from the binary logistic regression models for the association between independent variables and women's preconception healthcare knowledge while controlling covariates are presented in Table 4. The likelihood of having good 
TABLE 1: Sociodemographic characteristics of the childbearing age group women in Jinka town, Southern Ethiopia, $2018(n=513)$.

\begin{tabular}{|c|c|c|}
\hline Characteristics & Frequency & Percentage \\
\hline \multicolumn{3}{|l|}{ Age } \\
\hline $15-24$ & 259 & 50.5 \\
\hline $25-34$ & 176 & 34.3 \\
\hline $35-49$ & 78 & 15.2 \\
\hline \multicolumn{3}{|l|}{ Marital status } \\
\hline Married & 337 & 65.7 \\
\hline Single & 135 & 26.3 \\
\hline Divorced & 21 & 4.1 \\
\hline Widowed & 20 & 3.9 \\
\hline \multicolumn{3}{|l|}{ Maternal occupation status } \\
\hline Housewife & 208 & 40.5 \\
\hline Civil servant & 76 & 14.8 \\
\hline Merchant & 53 & 10.3 \\
\hline Day labourer & 28 & 5.5 \\
\hline Student & 137 & 26.7 \\
\hline Others (private, jobless) & 11 & 2.1 \\
\hline \multicolumn{3}{|l|}{ Maternal education status } \\
\hline No formal education & 68 & 13.3 \\
\hline Primary school & 157 & 30.6 \\
\hline Secondary school (9-12) & 155 & 30.2 \\
\hline College and above & 133 & 25.9 \\
\hline \multicolumn{3}{|l|}{ Husband's education status } \\
\hline No formal education & 21 & 4.1 \\
\hline Primary school & 85 & 16.6 \\
\hline Secondary school (9-12) & 100 & 19.5 \\
\hline College and above & 131 & $25.5 \%$ \\
\hline \multicolumn{3}{|l|}{ Husband's occupation } \\
\hline Government employee & 135 & 26.3 \\
\hline Merchant & 87 & 17.0 \\
\hline Day labourer & 63 & 12.3 \\
\hline Farmer & 19 & 3.7 \\
\hline Driver & 18 & 3.5 \\
\hline Others & 15 & 2.9 \\
\hline
\end{tabular}

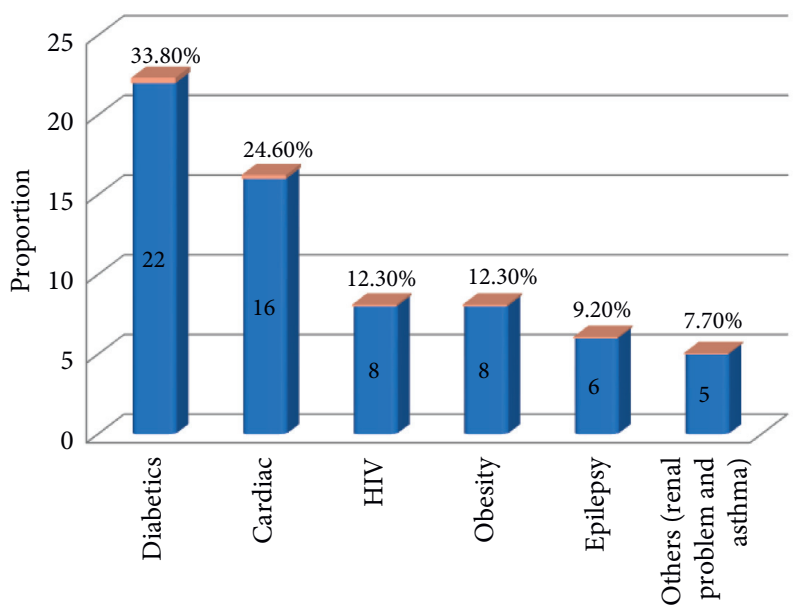

Chronic illness reported

FIgUre 2: Types of chronic health problems childbearing age women have in Jinka town, Southern Ethiopia, $2018(n=65)$.

preconception health knowledge was higher in housewives $(\mathrm{AOR}=2.93 ; 95 \% \quad \mathrm{CI}=1.38-6.19)$. Women who had
TABLE 2: Women's awareness of preconception healthcare in Jinka town, Southern Ethiopia, $2018(n=513)$.

\begin{tabular}{lcc}
\hline Variables & Frequency $(N)$ & Percentage (\%) \\
\hline Ever heard about preconception healthcare & \\
Yes & 312 & 60.8 \\
No & 201 & 39.2 \\
\hline Source of information for preconception care & \\
Healthcare provider & 254 & 49.5 \\
Mass media & 208 & 40.5 \\
Friends & 47 & 9.2 \\
Others & 4 & 0.8 \\
\hline Awareness on importance of preconception care & \\
Baby, only & 38 & 7.4 \\
Mother, only & 43 & 8.4 \\
Both baby and mother & 380 & 74.1 \\
Do not know & 52 & 10.1 \\
\hline Convenient place for preconception care provision & \\
Home & 56 & 10.9 \\
Health institution & 247 & 48.1 \\
Home and health & 148 & 28.8 \\
\hline Institution & 62 & 12.1 \\
Do not know &
\end{tabular}

attended primary education $(\mathrm{AOR}=2.06 ; \quad 95 \%$ $\mathrm{CI}=1.06-3.97)$, secondary education $(\mathrm{AOR}=2.77 ; 95 \%$ $\mathrm{CI}=1.38-5.57)$, and tertiary education $(\mathrm{AOR}=3.79 ; 95 \%$ $\mathrm{CI}=1.75-8.23)$ were more likely to have good preconception healthcare knowledge.

Last, the odds of having good preconception healthcare knowledge was higher in women who had no history of neonatal death $(\mathrm{AOR}=4.13 ; 95 \% \mathrm{CI}=1.39-12.25)$ and used family planning methods $(\mathrm{AOR}=2.38 ; 95 \% \mathrm{CI}=1.49-3.79)$.

\section{Discussion}

In this study, the overall study participants' knowledge of preconception healthcare was found to be $51.1 \%$. The findings in this study are higher than studies conducted in West Gojjam (27.5\%) [28], Saud Arabia (37.9\%) [33, 34], Nigeria 20.6\% [35], India (6\%) [36], Egypt (22\%) [37], Southeastern Nigeria (43.1\%) [38], and Sudan (11.1\%) [25]. This may be due to time variation; as time goes, women's understanding becomes better. Furthermore, in the case of the Sudanese and Saudi Arabian studies, a single component of preconception healthcare was addressed. In Gojjam, more than $34 \%$ of the study participants had an awareness of preconception healthcare than the $60 \%$ counterparts in the current study. In this study, more women $(87 \%)$ had attended at least primary education than women in Gojjam's does. The participation of rural women may also be a source of heterogeneity, and this study focuses on women living in urban areas.

A significant variation has been shown between this study and studies conducted in Jordan (85\%) [39], Iran (68.8\%) [40], and the USA (76\%) [41]. Women who live in the middle- to high-income countries have better information and Internet access and better media coverage. On 
TABLE 3: Women's knowledge of preconception health-related behavioural risk factors on the fetus in Jinka town, Southern Ethiopia, 2018 $(n=513)$.

\begin{tabular}{|c|c|c|}
\hline Variables & Frequency $(N)$ & Percentage (\%) \\
\hline \multicolumn{3}{|c|}{ Diabetes mellitus needs to be treated } \\
\hline Yes & 366 & 65.5 \\
\hline No & 177 & 34.5 \\
\hline \multicolumn{3}{|c|}{ Epilepsy should be treated } \\
\hline Yes & 312 & 60.8 \\
\hline No & 201 & 39.2 \\
\hline \multicolumn{3}{|c|}{ Uncontrolled obesity affects fetus health } \\
\hline Yes & 255 & 49.7 \\
\hline No & 258 & 50.3 \\
\hline \multicolumn{3}{|c|}{ Screening for STI and HIV/AIDS improves fetal life } \\
\hline Yes & 412 & 80.3 \\
\hline No & 101 & 19.7 \\
\hline \multicolumn{3}{|c|}{ Heart diseases should be treated } \\
\hline Yes & 319 & 62.2 \\
\hline No & 194 & 37.8 \\
\hline \multicolumn{3}{|c|}{ Stress and depression affect fetal life } \\
\hline Yes & 263 & 51.3 \\
\hline No & 250 & 48.7 \\
\hline \multicolumn{3}{|c|}{ Screening for genetic problem, lower adverse pregnancy outcome } \\
\hline Yes & 243 & 47.4 \\
\hline No & 270 & 52.6 \\
\hline \multicolumn{3}{|c|}{ Cigarette smoking should be avoided before conception } \\
\hline Yes & 445 & 86.7 \\
\hline No & 68 & 13.3 \\
\hline \multicolumn{3}{|c|}{ Alcohol consumption before conception result in poor pregnancy outcome } \\
\hline Yes & 426 & 83 \\
\hline No & 87 & 17 \\
\hline \multicolumn{3}{|c|}{ Exposure to environmental hazard leads to adverse perianal outcome } \\
\hline Yes & 127 & 24.1 \\
\hline No & 386 & 75.9 \\
\hline \multicolumn{3}{|c|}{ Illegal drug intake affects fetal wellbeing } \\
\hline Yes & 381 & 74.3 \\
\hline No & 132 & 25.7 \\
\hline \multicolumn{3}{|c|}{ Female genital mutilation complicates childbirth } \\
\hline Yes & 382 & 74.5 \\
\hline No & 131 & 25.5 \\
\hline
\end{tabular}

the other hand, a gap in creating awareness using public media may exist in the current study.

Indeed, preconception healthcare is not a part of the functioning healthcare system of Ethiopia. In the developed region, the presence of speciality clinics designed to give maternal care given by the accoucheur might enhance the women's interest in preconception healthcare. Indeed, most of the women presented in those clinics might have higher levels of education status.

However, the results reported in this study are relatively similar to the findings in Nepal (49\%) and Wolayita (53\%), Ethiopia, [27].

5.1. Factors of Women's Knowledge of Preconception Healthcare. The result of this study revealed that housewives were more likely to have preconception health knowledge. The current study finding is in agreement with a study conducted in China [42], where women's occupation determines their knowledge level. Housewives may have access to health information from health facilities because they usually bring their children to follow up [43]. Also, these women tend to have time to contact health extensions, friends, and healthcare providers, and Internet use.

This research finding speculated that women's level of education increases their knowledge of preconception healthcare. This is consistent with different studies conducted in Gojjam [28], China [42], Nigeria [35], Sudan [25], and Iran [40]. An educated woman has increased access to preconception care-related information more likely. Education can provide better information access and enhanced critical thinking in which women have access to preconception healthcare. The higher the 


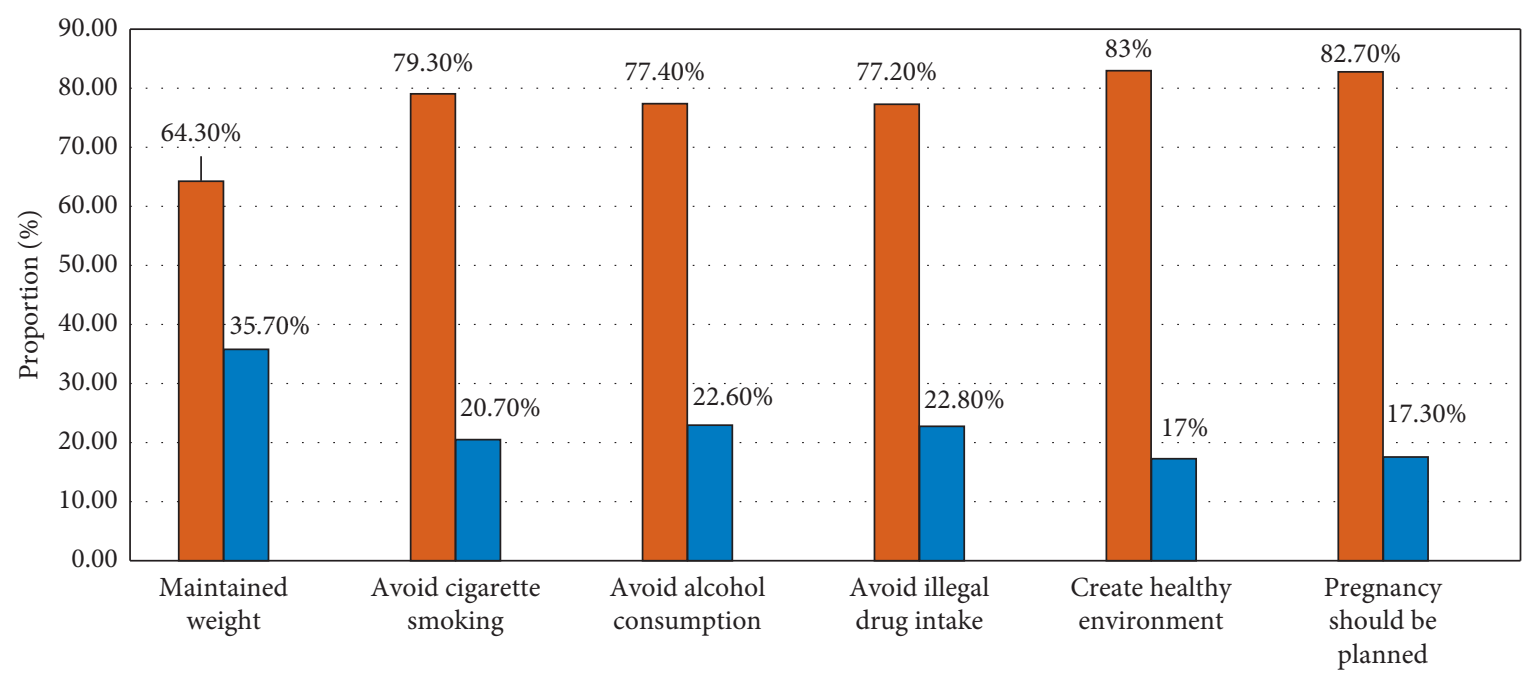

Changes need to be made during pregnancy

Yes

No

FIgURE 3: Women's knowledge of preconception care component in Jinka town, Southern Ethiopia, 2018.

TABLE 4: Factors associated with knowledge of preconception care among women in Jinka, Southern Ethiopia, 2018 ( $n=513$ ).

\begin{tabular}{|c|c|c|c|c|c|}
\hline \multirow{2}{*}{ Variables } & & \multicolumn{2}{|c|}{ Knowledge of PCHC } & \multirow{2}{*}{ Corollary (95\% CI) } & \multirow{2}{*}{ AOR $(95 \% \mathrm{CI})$} \\
\hline & & Good & Poor & & \\
\hline \multirow{6}{*}{ Women's occupation } & Housewife & $121(23.6 \%)$ & $87(17.0 \%)$ & $1.26(0.36-4.43)$ & $2.93(1.38-6.19)^{* *}$ \\
\hline & Civil servant & $16(3.1 \%)$ & $60(11.7 \%)$ & $6.56(1.71-25.2)$ & $1.38(0.72-2.63)$ \\
\hline & Merchant & $23(4.5 \%)$ & $30(5.8 \%)$ & $2.28(0.60-8.75)$ & $1.19(0.56-2.74)$ \\
\hline & Daily labourer & $15(2.9 \%)$ & $13(2.5 \%)$ & $1.52(0.36-6.37)$ & $1.11(0.60-2.1)$ \\
\hline & Student & $69(13.5 \%)$ & $68(13.3 \%)$ & $1.73(0.48-6.16)$ & $0.44(0.11-1.67)$ \\
\hline & Others & $7(1.4 \%)$ & $4(0.8 \%)$ & $1: 00$ & $1: 00$ \\
\hline \multirow{4}{*}{ Women's education } & No formal education & $50(9.7 \%)$ & $18(3.5 \%)$ & $1: 00$ & $1: 00$ \\
\hline & Primary education & $86(16.8 \%)$ & $71(13.8 \%)$ & $0.16(0.08-0$ & $2.06(1.06-3.97)^{*}$ \\
\hline & Secondary education & $75(14.6 \%)$ & $80(15.6 \%)$ & $0.36(0.22-0.58)$ & $2.77(1.38-5.57)^{* *}$ \\
\hline & College and above & $40(7.8 \%)$ & $93(18.1 \%)$ & $0.46(0.28-0.75)$ & $3.79(1.75-8.23)^{* *}$ \\
\hline \multirow{2}{*}{ History of neonatal death } & Yes & $20(3.9 \%)$ & $5(1 \%)$ & $1: 00$ & $1: 00$ \\
\hline & No & $139(27.1 \%)$ & $169(32.9 \%)$ & $4.86(1.78-13.3)$ & $4.13(1.39-12.25)^{*}$ \\
\hline \multirow{2}{*}{ History of family planning use } & Yes & $126(24.6 \%)$ & $178(34.7 \%)$ & $2.1(1.47-3.01)$ & $2.38(1.49-3.79)^{\text {*** }}$ \\
\hline & No & $125(26.4 \%)$ & $84(16.4 \%)$ & $1: 00$ & $1: 00$ \\
\hline
\end{tabular}

*, $p$ value $<0.05 ;{ }^{* *}, p$ value $<0.01 ;{ }^{* * *}, p$ value $<0.001$

women's education level, the better she understands preconception healthcare services and has a favourable attitude on similar issues [44]. Scientifically speaking, highly educated people have greater intentions to prepare for their pregnancy [45].

This study showed that women who had no history of neonatal death have an increased probability of knowing about preconception healthcare. The hypothesis to explain the possible reason for this may be due to parental stress and heightened anxiety because of the adverse outcome attributes [45]. In this case, the women may be at increased risk of an unplanned pregnancy because of an increased desire to have another baby. The current study finding is not consistent with a study performed in the Netherlands, Australia [46], and this might be due to study design differences, access to information and maternal health-seeking behaviours, and providers' counselling approach. Concerning family planning, women who used family planning methods were more knowledgeable. This finding is consistent with a study conducted in France [47], Gojjam, and Sudanese [25, 28]. Since planning a pregnancy is a vital component of $\mathrm{PCH}$ $[48,49]$, women who had access to family planning services might know about the risk of an unplanned pregnancy.

5.2. Limitations of This Study. The use of cross-sectional study design in this study may affect the causation for an alternative explanation of association. Self-reporting might have a social desirability bias. One of the limitations of this study was the lack of data on an obstetric parameter such as a delivery week, delivery mode, and birth weight. Given the 
limited factors addressed in this research, future research should consider healthcare providers and institutional-related factors [49].

\section{Conclusion}

The finding of this study shows a relatively satisfactory knowledge of preconception healthcare. In Jinka town, the probability of having good preconception healthcare increases when women become housewives, had formal education attendance, no history of neonatal death, and a history of family planning methods use. Therefore, the town health office needs to establish a preconception healthcare strategy in which it focuses on women's education and family planning use promotion. Moreover, women empowerment and knowledge improvement tailored to the community context involving essential stakeholders is mandatory.

\section{Abbreviations}

CI: $\quad$ Confidence interval

LMIC: Low- and middle-income country

PCHC: Preconception healthcare

WHO: World Health Organization.

\section{Data Availability}

The datasets generated during the current study are available from the corresponding author upon request.

\section{Ethical Approval}

This study was approved by the Arba Minch University College of Medicine and Health Sciences' Ethical Review Board.

\section{Consent}

Informed verbal consent was obtained from all of the study participants.

\section{Conflicts of Interest}

The authors declare that they have no conflicts of interest.

\section{Authors' Contributions}

TC, AA, MF, BB, HM, EK, and GW contributed to the conception, formulation, design, analysis, interpretation, drafting of the research report, and final approval of the manuscript. KF contributed to design, analysis, interpretation, drafting of the research report, revision, and final approval of the manuscript. All authors have read and approved the final manuscript.

\section{Acknowledgments}

The authors would like to thank and express their deeprooted gratitude to Arba Minch University College of
Medicine and Health Science' Ethical Review Board for the approval of ethical clearance. The authors are also thankful to study participants for their willingness to participate in the study.

\section{References}

[1] K. Johnson, S. F. Posner, J. Biermann et al., "Recommendations to improve preconception health and Health Care-United States: report of the CDC/ATSDR preconception care workgroup and the select panel on preconception care," Morbidity and Mortality Weekly Report: Recommendations and Reports, vol. 55, no. 6, pp. 1-4, 2006.

[2] K. J. Kerber, J. E. de Graft-Johnson, Z. A. Bhutta, P. Okong, A. Starrs, and J. E. Lawn, "Continuum of care for maternal, newborn, and child health: from slogan to service delivery," The Lancet, vol. 370, no. 9595, p. 1358, 2007.

[3] M. Röbl-Mathieu, "Nachhaltige Förderung der Frauengesundheit durch Preconception Counseling," Geburtsh Frauenheilk, vol. 75, pp. 1243-1249, 2015.

[4] A. Berglund and G. Lindmark, "Preconception health and care (PHC)-a strategy for improved maternal and child health," Upsala Journal of Medical Sciences, vol. 121, no. 4, pp. 216-221, 2016.

[5] World Health Organization, Meeting to Develop a Global Consensus on Preconception Care to Reduce Maternal and Childhood Mortality and Morbidity, World Health Organization, Geneva, Switzerland, 2013.

[6] L. Charafeddine, R. El Rafei, S. Azizi et al., "Improving awareness of preconception health among adolescents: an experience of a school-based intervention in Lebanon," BMC Public Health, vol. 14, no. 1, p. 774, 2014.

[7] J. Biermann, A. L. Dunlop, C. Brady, C. Dubin, and A. Brann, "Promising practices in preconception care for women at risk for poor health and pregnancy outcomes," Maternal and Child Health Journal, vol. 10, no. 1, pp. 21-28, 2006.

[8] S. L. Boulet, C. Parker, and H. Atrash, "Preconception care in international settings," Maternal and Child Health Journal, vol. 10, no. 1, pp. 29-35, 2006.

[9] H. K. Atrash, K. Johnson, M. M. Adams, J. F. Cordero, and J. Howse, "Preconception care for improving perinatal outcomes: the time to act," Maternal and Child Health Journal, vol. 10, no. 1, pp. 3-11, 2006.

[10] M. M. Adams, L. D. Elam-Evans, H. G. Wilson, and D. A. Gilbertz, "Rates of and factors associated with recurrence of preterm delivery," Jama, vol. 283, no. 12, pp. 1591-1596, 2000.

[11] R. L. Goldenberg and J. F. Culhane, "Prepregnancy health status and the risk of preterm delivery," Archives of Pediatrics \& Adolescent Medicine, vol. 159, no. 1, pp. 89-90, 2005.

[12] M. Patabendige and I. Goonewardene, "Preconception care received by women attending antenatal clinics at a Teaching Hospital in Southern Sri Lanka," Sri Lanka Journal of Obstetrics and Gynaecology, vol. 35, no. 1, 2013.

[13] Q. Zhou, G. Acharya, S. Zhang, Q. Wang, H. Shen, and X. Li, "A new perspective on universal preconception care in China," Acta obstetricia et Gynecologica Scandinavica, vol. 95, no. 4, pp. 377-381, 2016.

[14] K. Duckitt and D. Harrington, "Risk factors for pre-eclampsia at antenatal booking: systematic review of controlled studies," BMJ, vol. 330, no. 7491, p. 565, 2005.

[15] Y. Yanase, S. Luewan, and T. Tongsong, "Pregnancy outcome in chronic hypertensive pregnant women in Maharaj Nakorn 
Chiangmai Hospital," Thai Journal of Obstetrics and Gynaecology, vol. 17, 2009.

[16] C. A. Crowther, J. E. Hiller, J. R. Moss, A. J. McPhee, W. S. Jeffries, and J. S. Robinson, "Effect of treatment of gestational diabetes mellitus on pregnancy outcomes," New England Journal of Medicine, vol. 352, no. 24, pp. 2477-2486, 2005.

[17] J. P. Bestwick, W. J. Huttly, J. K. Morris, and N. J. Wald, "Prevention of neural tube defects: a cross-sectional study of the uptake of folic acid supplementation in nearly half a million women," PloS One, vol. 9, no. 2, 2014.

[18] N. Li, E. Liu, J. Guo et al., "Maternal prepregnancy body mass index and gestational weight gain on pregnancy outcomes," PloS One, vol. 8, no. 12, 2013.

[19] D. Shin and W. O. Song, "Prepregnancy body mass index is an independent risk factor for gestational hypertension, gestational diabetes, preterm labor, and small- and large-forgestational-age infants," The Journal of Maternal-Fetal of Neonatal Medicine, vol. 28, no. 14, pp. 1679-1686, 2015.

[20] P. De Wals, F. Tairou, M. I. Van Allen et al., "Reduction in neural-tube defects after folic acid fortification in Canada," New England Journal of Medicine, vol. 357, no. 2, pp. 135-142, 2007.

[21] B. W. Jack, H. Atrash, D. V. Coonrod, M.-K. Moos, J. O'Donnell, and K. Johnson, “The clinical content of preconception care: an overview and preparation of this supplement," American Journal of Obstetrics and Gynecology, vol. 199, no. 6, pp. S266-S279, 2008.

[22] M.-K. Moos, A. L. Dunlop, B. W. Jack et al., "Healthier women, healthier reproductive outcomes: recommendations for the routine care of all women of reproductive age," American Journal of Obstetrics and Gynecology, vol. 199, no. 6, pp. S280-S289, 2008.

[23] R. Kasim, N. Draman, A. A. Kadir, and R. Muhamad, "Knowledge, attitudes and practice of preconception care among women attending maternal health clinic in Kelantan," Education in Medicine Journal, vol. 8, no. 4, 2016.

[24] W. Al Darzi, F. Al Mudares, A. Farah, A. Ali, and D. Marzouk, "Knowledge of periconceptional folic acid use among pregnant women at Ain Shams University Hospital, Cairo, Egypt," Eastern Mediterranean Health Journal, vol. 20, no. 09, pp. 561-568, 2014.

[25] K. Ahmed, I. M. H. Elbashir, S. M. Ibrahim, A. K. M. Mohamed, and A. A. M. Alawad, "Knowledge, attitude and practice of preconception care among Sudanese women in reproductive age about rheumatic heart disease at Alshaab and Ahmad Gassim hospitals 2014-2015 in Sudan," Journal of Basic Research in Medical Sciences, vol. 4, no. 7, p. 5, 2015.

[26] A. Olowokere, A. Komolafe, and C. Owofadeju, "Awareness, knowledge and uptake of preconception care among women in ife central local government area of osun state, Nigeria," Journal of Community Medicine and Primary Health Care, vol. 27, no. 2, pp. 83-92, 2015.

[27] Z. Y. Kassa, Z. Tenaw, A. Astatkie et al., "Mobile phone-based strategies for preconception education in Rural Africa," Annals of Global Health, vol. 85, no. 1, 2019.

[28] Y. Ayalew, A. Mulat, M. Dile, and A. Simegn, "Women's knowledge and associated factors in preconception care in adet, west gojjam, northwest Ethiopia: a community-based cross-sectional study," Reproductive Health, vol. 14, no. 1, p. 15, 2017.

[29] A. Kassa, S. P. Human, and H. Gemeda, "Knowledge of preconception care among healthcare providers working in public health institutions in Hawassa, Ethiopia," PloS One, vol. 13, no. 10, Article ID e0204415, 2018.

[30] M. M. Bekele, N. A. Gebeyehu, M. M. Kefale, and S. A. Bante, "Knowledge of preconception care and associated factors among healthcare providers working in public health institutions in awi Zone, north west Ethiopia, 2019: institutionalbased cross-sectional study," Journal of Pregnancy, vol. 2020, Article ID 6978171, 7 pages, 2020.

[31] Central Statistical Agency MPC, Ethiopia-population and Housing Census of 2007, Central Statistical Agency-Ministry of Finance and Economic Development, Delhi, India, 2007.

[32] "Knowledge about preconception care in French women with type 1 diabetes," Diabetes \& Metabolism, vol. 31, no. 5, pp. 443-447, 2005.

[33] P. Gautan and R. Dhakal, "Knowledge on preconception care among reproductive-age women," Saudi Journal of Medical and Pharmaceutical Sciences, vol. 2, no. 1, p. 6, 2016.

[34] A. Madanat and E. Sheshah, "Preconception care in Saudi women with diabetes mellitus," Journal of Family and Community Medicine, vol. 23, no. 2, pp. 109-114, 2016.

[35] A. Umar, S. Nasir, K. Tunau, S. Singh, U. Ibrahim, and M. Hassan, "Awareness and perception of preconception care among women in usmanu danfodiyo university teaching hospital sokoto, north-western Nigeria," Journal of Family Medicine and Primary Care, vol. 8, no. 5, pp. 1696-1700, 2019.

[36] P. G. Patel and T. A. Shah, "Assessment of knowledge and attitude regarding pre-conceptional care among newly married women residing at urban areas of vadodara city, Gujarat, India," National Journal of Maxillofacial Surgery, vol. 10, no. 12, pp. 649-652, 2019.

[37] F. A. Mosalem, A. Azza, T. M. Refaat, and E. A. Emam, "Awareness of primary health care providers in el-minia governorate about preconception care," PLoS One, vol. 13, 2011.

[38] H. U. Ezegwui, C. Dim, N. Dim, and A. C. Ikeme, "Preconception care in South eastern Nigeria," Journal of $\mathrm{Ob}$ stetrics and Gynaecology, vol. 28, no. 8, p. 765, 2008.

[39] N. A. Al-Akour, R. Sou'Ub, K. Mohammad, and F. Zayed, "Awareness of preconception care among women and men: a study from Jordan," Journal of Obstetrics and Gynaecology, vol. 35, no. 3, pp. 246-250, 2015.

[40] F. Jafari and S. Rashidi, “Iranian women's knowledge and attitude regarding preconception health: 12 years after integration into the primary health care network," Journal of Nursing and Midwifery Sciences, vol. 4, no. 3, p. 104, 2017.

[41] D. V. Coonrod, N. C. Bruce, T. D. Malcolm, D. Drachman, and K. A. Frey, "Knowledge and attitudes regarding preconception care in a predominantly low-income Mexican American population," American Journal of Obstetrics and Gynaecology, vol. 200, no. 6, pp. e1-e7, 2009.

[42] X. Zhao, X. Jiang, J. Zhu et al., "Factors influencing the quality of preconception healthcare in China: applying a preconceptional instrument to assess healthcare needs," BMC Pregnancy and Childbirth, vol. 14, no. 1, p. 360, 2014.

[43] M. Rahman, N. A. Rahim, and M. T. Arif, "Barrier, weakness and utilization of pre-pregnancy clinic services," Archives of Public Health, vol. 75, no. 1, p. 67, 2017.

[44] C. Yu and X. Li, "Two-level logistic modelling analysis on the factors that influence birth in hospitals in poor rural areas of Sichuan province," Sichuan da Xue Xue bao Yi Xue ban=Journal of Sichuan University Medical science edition, vol. 39, no. 6, pp. 1011-1013, 2008.

[45] J. Lumley and L. Donohue, "Aiming to increase birth weight: a randomised trial of pre-pregnancy information, advice and 
counselling in inner-urban Melbourne," BMC Public Health, vol. 6, no. 1, p. 299, 2006.

[46] J. Elsinga, L. C. De Jong-Potjer, K. M. Van Der Pal-De Bruin, S. Le Cessie, W. J. J. Assendelft, and S. E. Buitendijk, "The effect of preconception counselling on lifestyle and other behaviour before and during pregnancy," Women's Health Issues, vol. 18, no. 6, pp. S117-S125, 2008.

[47] J. Lepercq, "Knowledge about preconception care in french women with type 1 diabetes," Diabetes \& Metabolism, vol. 31, 2008.

[48] C. Heath and S. M. Sulik, "Contraception and preconception counselling," Primary Care, vol. 24, no. 1, pp. 123-133, 1997.

[49] E. C. Miller, N. Liu, S. W. Wen, and M. Walker, "Why do Canadian women fail to achieve optimal pre-conceptional folic acid supplementation? An observational study," Journal of Obstetrics and Gynaecology Canada, vol. 33, no. 11, pp. 1116-1123, 2011. 